\title{
MAPA GEOGRÁFICO: APRESENTAÇÃO E BREVE ESTUDO DE DOCUMENTO RELATIVO AO CAMINHO PARA AS MINAS
}

\author{
Maria Antonieta Amarante de Mendonça Cohen*
}

\begin{abstract}
Resumo: Apresenta-se neste artigo um texto em língua portuguesa, provavelmente setecentista, que descreve o caminho para as Minas, a partir de São Paulo ou do Rio de Janeiro. Este texto existe em vários testemunhos impressos e manuscritos. Serão apresentadas suas características gerais e discussão das etapas já cumpridas de sua edição em preparação.

Palavras-chave: Crítica textual; século XVIII; manuscrito; itinerário.
\end{abstract}

O texto que ora se apresenta, a que denominamos resumidamente Mapa geográfico, chegou ao nosso conhecimento em decorrência de estudos iniciados com o projeto Filologia bandeirante,${ }^{1}$ que teve como objetivo final o estudo da língua portuguesa que pretensamente se teria expandido de São Paulo para as minas do ouro, tendo como roteiro a bandeira de 1674 , do famoso Fernão Dias Paes Leme. Dando-lhe continuidade, o projeto Pelas trilhas de Minas: as bandeiras e a língua nas Gerais ${ }^{2}$

\footnotetext{
* Universidade Federal de Minas Gerais.

${ }^{1}$ Projeto apoiado pela Fapesp, de 1998 a 2001 que reunia equipes da USP, UFMT, UFG e UFMG.

${ }^{2}$ Projeto apoiado pela Fapemig.
} 
passou a focalizar a língua no território mineiro, concomitante à efervescência que a lei de incentivo à conservação da famosa Estrada $\mathrm{Real}^{3}$ trouxe, atraindo pesquisadores de várias áreas. Mesmo os estudos voltados para questões linguísticas incluíram dados de contextualização da época de descoberta e exploração das minas e, nessa frente de trabalho, mapas, cartas geográficas que descrevessem os caminhos para as minas daqueles que "iam para o sertão", como colocado por Megale,${ }^{4}$ foram material de trabalho indispensável.

O mapa que serviu de base ao início dos trabalhos foi o de Simão de Vasconcellos e este contato ensejou a busca de outros, incluindo-se o Mapa geográfico de que tratamos aqui. Neste fazse a descrição do caminho para as minas através de um texto escrito em língua portuguesa. Assim o objetivo de conhecimento dos caminhos para as minas do ouro e o linguístico se acoplaram.

Neste universo insere-se esta apresentação e estudo do texto cujo título que figura em alguns de seus testemunhos mais recentes, como o do que se encontra no Códice Costa Matoso ${ }^{5}$ é Itinerário geográfico com a verdadeira descrição dos caminbos, estradas, roças, sítios, povoações, lugares, vilas, rios, montes, $e$ serras, que bá da cidade de S. Sebastião do Rio de Janeiro até as Minas do Ouro.

Apresentamos aqui a tradição desse documento relativo ao caminho que, partindo de São Paulo ou do Rio de Janeiro, levava às lavras de ouro e de pedras preciosas no século XVIII, se não antes, no território que vem a ser Minas Gerais. Tal caminho desdobrava-se em vários roteiros e recuperava antigas trilhas utilizadas pelos índios, como colocado por Venâncio ${ }^{6}$ vindo a configurar o caminho conhecido como Estrada Real.

\footnotetext{
${ }^{3}$ Lei n. 13.173, de 20.01.99, pela conservação da Estrada Real.

${ }^{4}$ MEGALE. Bandeira e Bandeirante, p. 21.

${ }^{5}$ CAMPOS; ALMEIDA FIGUEIREDO. Códice Costa Matoso.

${ }^{6}$ VENÂNCIO. Caminho novo: a longa duração.
} 
O texto em questão não é um documento literário, é antes descritivo e em poucas passagens percebe-se a presença de um sujeito que se posiciona quanto ao que está sendo descrito. Depois de listas de topônimos e hidrônimos, às vezes escapa uma apreciação do copista, como nesta passagem: "em pouco mais detres / horas sevençe aemi/nencia daquellaSerra / daq. ${ }^{\text {al }}$ seve omar eapla/nicie da Terra comoni/cada das transparentes Águas de infinitos Rios / q. servem p. ${ }^{\text {a }}$ avista de agra / davel e lizongr ${ }^{\circ}$. objecto" (ms. 54-XIII4 n.24, Bibl. da Ajuda, f. 1v)

O gênero e estilo do exórdio presente nos testemunhos impressos e no ms.148 da Biblioteca Geral da Universidade de Coimbra diferem deste descritivo do mapa geográfico propriamente: é laudatório, encomiástico, como já observado pelos editores do Códice Costa Matoso. Esta diferença de gênero indica que a introdução lhe foi acrescida e faz-nos supor que há um testemunho mais antigo, provavelmente um dos em que falta uma introdução.

Reveste-se esse documento de importância para o conhecimento da língua portuguesa da época em que foi escrito e do contexto histórico que o produziu. O documento existe em vários testemunhos, sendo que apenas a versão impressa antiga é datada: 1732. Esta é a data de referência para que os enquadremos no século XVIII. Suas versões ou testemunhos podem ser divididos em dois grupos, a tradição impressa e a manuscrita.

\section{Tradição impressa}

O testemunho mais conhecido e disponível em cópias públicas, dentre os que se apresentam neste trabalho, é a versão impressa de 1732, de Sevilha, "na Officina de Antonio Sylva". Esse documento foi classificado como raro e secreto por Livermore. ${ }^{7}$

\footnotetext{
${ }^{7}$ LIVERMORE. An early published guide to Minas Gerais: the ITINERARIO GEOGRAFICO (1732), p. 4-10.
} 
Raro, porque ele próprio teve acesso a dois testemunhos, um impresso e um manuscrito; secreto, pelo tipo de informação que veicula, referente às minas do ouro e de pedras preciosas, que por algum tempo apenas secretamente circulava na Europa. Acrescente-se a isso o fato de o texto não ser citado nas obras dos historiadores que se ocuparam do século XVIII, à exceção de Lima Jr., ${ }^{8}$ que lhe faz referência.

Segundo Livermore, ${ }^{9}$ o texto dificilmente teria sido publicado em Sevilha, porque não consta que houvesse à época, na Andaluzia, tipografias de nome Sylva, que imprimissem com letra portuguesa e com características tais com as vinhetas tipicamente portuguesas que apresenta. Essa indefinição sobre o local de publicação, esta visível camuflagem, dever-se-ia ao teor secreto das informações que continha sobre os caminhos para as minas do ouro no Brasil.

Os testemunhos impressos são todos idênticos, e contam, para fins de edição, como uma só. São eles (indica-se entre parênteses a sigla aqui adotada):

a) da revista Barroco (RB): BRITO, Francisco Tavares de. Itinerario geografico com a verdadeira descripçaõ dos Caminbos, Estradas, Rossas, Citios, Povoaçõens, Lugares, Villas, Rios, Montes, e Serras, que Ha da cidade de S. Sebastiaõ do Rio de Janeiro. Atè as Minas do Ouro. Sevilha, 1732. Barroco, Belo Horizonte,v. 4, p. 91-118, 1972. (Edição fac-similar).

b) da John Carter Brown Library (JCB), Providence, EUA: BRITO, Francisco Tavares de. Itinerario geografico com a verdadeira descripçaõ dos Caminhos, Estradas, Rossas, Citios, Povoaçõens, Lugares, Villas, Rios, Montes, e Serras, que Ha da cidade de S. Sebastiã̃ do Rio de Janeiro. Atè as Minas do Ouro. Sevilha, 1732.

\footnotetext{
${ }^{8}$ LIMA JR. A capitania das Minas Gerais, p. 28.

9 LIVERMORE. An early published guide to Minas Gerais: the ITINERARIO GEOGRAFICO (1732), p. 4-10.
} 
c) da Biblioteca Nacional de Portugal (DP): BRITO, Francisco Tavares de. Itinerario geografico com a verdadeira descripçaõ dos Caminhos, Estradas, Rossas, Citios, Povoaçõens, Lugares, Villas, Rios, Montes, e Serras, que Ha da cidade de S. Sebastiaõ do Rio de Janeiro. Atè as Minas do Ouro. Sevilha, 1732. (Digitalizada).

d) a da Revista do Instituto Histórico e Geográfico de São Paulo (IHGSP): ORVILE, D. Um mapa antigo da partes das capitanias de São Paulo, Minas Gerais e Rio de Janeiro. Revista do Instituto Histórico e Geográfico de São Paulo, São Paulo, v. 2, p.197-219, 1898.

e) a da Revista do Instituto Histórico e Geográfico Brasileiro (IHGB): Itinerario geografico com a verdadeira descripçã̃ dos Caminbos, Estradas, Rossas, Citios, Povoaçõens, Lugares, Villas, Rios, Montes, e Serras, que Ha da cidade de S. Sebastiaõ do Rio de Janeiro. Atè as Minas do Ouro. Revista do Instituto Histórico e Geográfico Brasileiro, Rio de Janeiro, v. 20, p. 430-441, 1956.

Há também uma versão impressa transcrita e modernizada, cujo conteúdo é igual aos testemunhos impressos do século XVIII:

f) a do Códice Costa Matoso, de 1999: ${ }^{10}$ BRITO, Francisco Tavares de. Itinerário geográfico com a verdadeira descrição dos caminhos, estradas, roças, sítios, povoações, lugares, vilas, rios, montes e serras que bá da cidade de São Sebastião do Rio de Janeiro até as Minas de Ouro. Composto por Francisco Tavares de Brito. Na Oficina de Antonio da Silva. MDCCCXXXII [1732].

Com a facilidade da reprodução por digitalização e microfilmagem de que se dispõe hoje, bem como da internet, muitos textos antigos são disponibilizados virtualmente. Dos testemunhos impressos, tomaremos como base a cópia digitalizada da Biblioteca Nacional Digital de Portugal.

\footnotetext{
${ }^{10}$ CAMPOS; ALMEIDA FIGUEIREDO. Códice Costa Matoso.
} 


\section{Tradição manuscrita}

As versões manuscritas não fazem referência a Francisco Tavares de Brito, o organizador, copilador do texto impresso. Até o momento três são os testemunhos a que tivemos acesso (indicase entre parênteses a sigla aqui adotada):

a) o da Biblioteca Geral da Universidade de Coimbra, ms.148, ff. 1-16 (C);

b) o da Biblioteca da Ajuda, Lisboa, Portugal, ms. 54-XIII-4 n.24 (L); e

c) o da Biblioteca Pública de Évora, ms. CXVI/2-13, n. 30 (E).

Esses testemunhos não são datados. Presume-se que sejam da mesma época do de Sevilha, talvez anteriores, e que possam lhe ter servido de modelo. Livermore ${ }^{11}$ compara a cópia impressa ao ms. C e chega a algumas conclusões, apesar de não ter se utilizado de metodologia da edição crítica de textos. Refere-se à presença de vários símbolos, que se assemelham a referências a uma carta geográfica, e sugere que anexo ao texto escrito deve ter havido um mapa, ao qual não se teve acesso:

ele de fato apresentou uma descrição para acompanhar um mapa à maneira de um guia, deixando de fora o mapa e as referências cartográficas a ele,de tal forma que os nomes identificados no mapa por números ou símbolos são colocados juntos, o que é às vezes ininteligível. (Tradução nossa) ${ }^{12}$

\footnotetext{
${ }^{11}$ LIVERMORE. An early published guide to Minas Gerais: the ITINERARIO GEOGRAFICO (1732), p. 4-10.

${ }^{12}$ LIVERMORE. An early published guide to Minas Gerais: the ITINERARIO GEOGRAFICO (1732), p. 4. [No original: "He has in fact presented a description intended to accompany a map in the guise of a guide, leaving out the map and all the cartographical references to it, so that names identified on the map by numbers or symbols are run together, and become at times unintelligible"].
} 
Prossegue comparando os títulos, que são diferentes: o impresso é o já referido Itinerario geografico com a verdadeira descripçaõ dos Caminhos, Estradas, Rossas, Citios, Povoaçõens, Lugares, Villas, Rios, Montes, e Serras, que Ha da cidade de S. Sebastiã̃ do Rio de Janeiro. Atè as Minas do Ouro. Sevilha, (1732); no manuscrito é apenas DESCRIPÇAM do Mapa geographico $q$. Comprebende os lemites do governo de S. Paulo, E Minas, e também os do Rio de Janeiro.

As palavras mais eruditas do manuscrito são substituídas no Itinerário impresso: íncola por babitante, inexplicável trabalbo por bastante trabalbo, e outras, que indicam para esse documento um público-leitor menos culto que o da Descripçam do ms. C.

Livermore não tem dúvida de que o Itinerário ${ }^{13}$ é posterior à Descripçam devido a uma passagem que neste existe, mas não naquele, em que se noticia o descobrimento de diamantes no Serro Frio, o que é um evento datado. Portanto, em 1732 esta informação já existia, mas não antes. Se o texto de $C$ não possui essa passagem, pode-se supor, como o fez o autor citado, que tal mina de diamantes não tinha ainda sido descoberta, o que retrocede a datação da Descripçam para antes de 1732.

Nos manuscritos aparecem duas variantes de um topônimo-Parição (C, f. 4) Aparição (L, f. 2r) Parição (E, f. 2) - em localidade próxima a Guaratinguetá que, segundo Andrade Gomes $^{14}$ é a atual Aparecida do Norte, no Estado de São Paulo. Supondo que o topônimo se refira ao encontro da imagem, da aparição da santa, pode-se estabelecer o terminus a quo desses manuscritos: não podem ser anteriores ao evento, datado de 1717. Leia-se a passagem, em que os lugares são descritos (negrito nosso):

Va. de Taubaté / Va. de Pundmunhangaba / Va. de Guaratingeta / A esta Va. tão bem vem dar / o Cam $^{\circ}$ de Parati que chamão / o Cam ${ }^{\circ}$

\footnotetext{
${ }^{13}$ Utilizamos Itinerário sempre para nos referirmos ao texto impresso.

${ }^{14}$ ANDRADE GOMES. Índice toponímico: nota introdutória, p. 155.
} 
Velho eq ${ }^{\mathrm{m}}$ sae de Parati / vem dar ao / Bananal, sobesce a innacessivel / serra e sedescanca na / Parição (E, f. 2)

Da nossa leitura deduzimos que os três manuscritos, incluindo-se o de Coimbra, não podem datar de antes de 1717, data da pesca da imagem da santa negra, que vem a ser $\mathrm{N}$. Sra. Aparecida, no atual Rio Paraíba do Sul, na época Pirapitinga, próximo à então Vila do Guaratinguetá (E, f. 2), atual Guaratinguetá, no Estado de São Paulo. Portanto, confirmamos a hipótese de Livermore: a Descripçam deve datar de antes de 1732 , e a partir de 1717 , ou seja, entre esses dois marcos: 1717-1732.

Trata-se, portanto, de codices plurimi ou texto politestemunhal, ${ }^{15}$ o que torna mais complexos sua transcrição e seu estudo, pois as etapas de collatio (comparação) e stemma codicum (classificação em famílias) serão necessárias, o que não é o caso se o texto é um codex unicus ou monotestemunhal.

Procedemos a uma classificação preliminar da tradição deste texto, que se coloca, como explicamos em seguida, levandose em conta algumas das informações da análise do Livermore.

$\mathrm{O}$ último testemunho manuscrito a que tivemos acesso foi o de Coimbra (C). Verificamos que este difere dos outros dois manuscritos, de Évora (E) e da Ajuda (L), por possuir uma introdução, como os testemunhos impressos. Assim todos os testemunhos impressos e o ms. C possuem alguns parágrafos introdutórios, num gênero nitidamente encomiástico, que difere da pouquíssimo adjetivada descrição do caminho para as minas que lhes segue. Essa introdução começa assim (negrito nosso):

$\mathrm{C}$ : Eu emprehendi ordenar, e descrever uma mapa geographico

DP: Eu emprehendi ordenar, e descrever hum Itinerario Geografico

Quanto a este aspecto, da presença ou ausência do exórdio, que se toma aqui como um dos loci critici, os testemunhos impressos se assemelham a $C$ e poderíamos supor que a cópia impressa de

${ }^{15}$ CAMBRAIA. Iniciação a crítica textual, p. 91. 
Sevilha tenha o testemunho de Coimbra como seu modelo, apesar das variantes presentes nas duas introduções. Essa análise é ainda preliminar, mas tendemos a considerar que esse exórdio é um acréscimo não genuíno, o que o tornaria um erro conjuntivo entre o testemunho $\mathrm{C}$ e as edições impressas.

Levantamos preliminarmente, assim, a seguinte hipótese, a ser refinada, da genealogia desse texto:

(1)

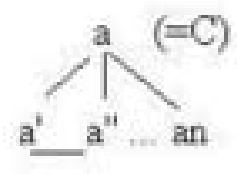

(ii)

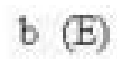

(iii)

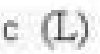

$\mathbf{a}\left(=\mathrm{C}\right.$, manuscrito) dá origem às cópias impressas $\mathbf{a}^{\prime}, \mathbf{a}^{\prime} \ldots \mathbf{a}^{\mathbf{n}}, \mathbf{a}$ despeito da presença de variantes. Os impressos idênticos poderão ser eliminados, ficando apenas um deles como exemplar de colação: a'. b $(=\mathrm{E})$ e c $(=\mathrm{L})$ se mantêm como testemunhos distintos, pois apresentam variantes.

Dos três testemunhos manuscritos, C é que se encontra em melhor estado de conservação, com caligrafia legível e organizada. Foi por nós escolhido como exemplar de colação, uma vez que, como já se pode adiantar, será necessária uma edição crítica deste texto.

Um dos preceitos da edição crítica de textos é que o público a que se destina uma edição ilumina, define os procedimentos a serem adotados pelo editor: nossa transcrição que tem como objetivo a pesquisa linguística, a descrição de sincronias linguísticas pretéritas adota para tanto as normas e os procedimentos visando esse fim.

Como se sabe, os documentos redigidos em língua portuguesa dessa época refletem uma modalidade de língua escrita lusitana, mas, por se referirem às cousas do Brasil, como o Itinerário, 
registram presença de toponímia de origem indígena, como Paranampiacaba, Paraibuna, Carijós, Titiaya (Itatiaia), Theeté (Tietê), lado a lado à de origem portuguesa, como nos antropotopônimos Amaro Ribeiro, Lana, Gonçalves, Araújo, dentre outros.

Apresentamos a seguir dois fólios do texto em questão: f. 3 do ms. C e p. 4 [= p. I] do impresso DP.

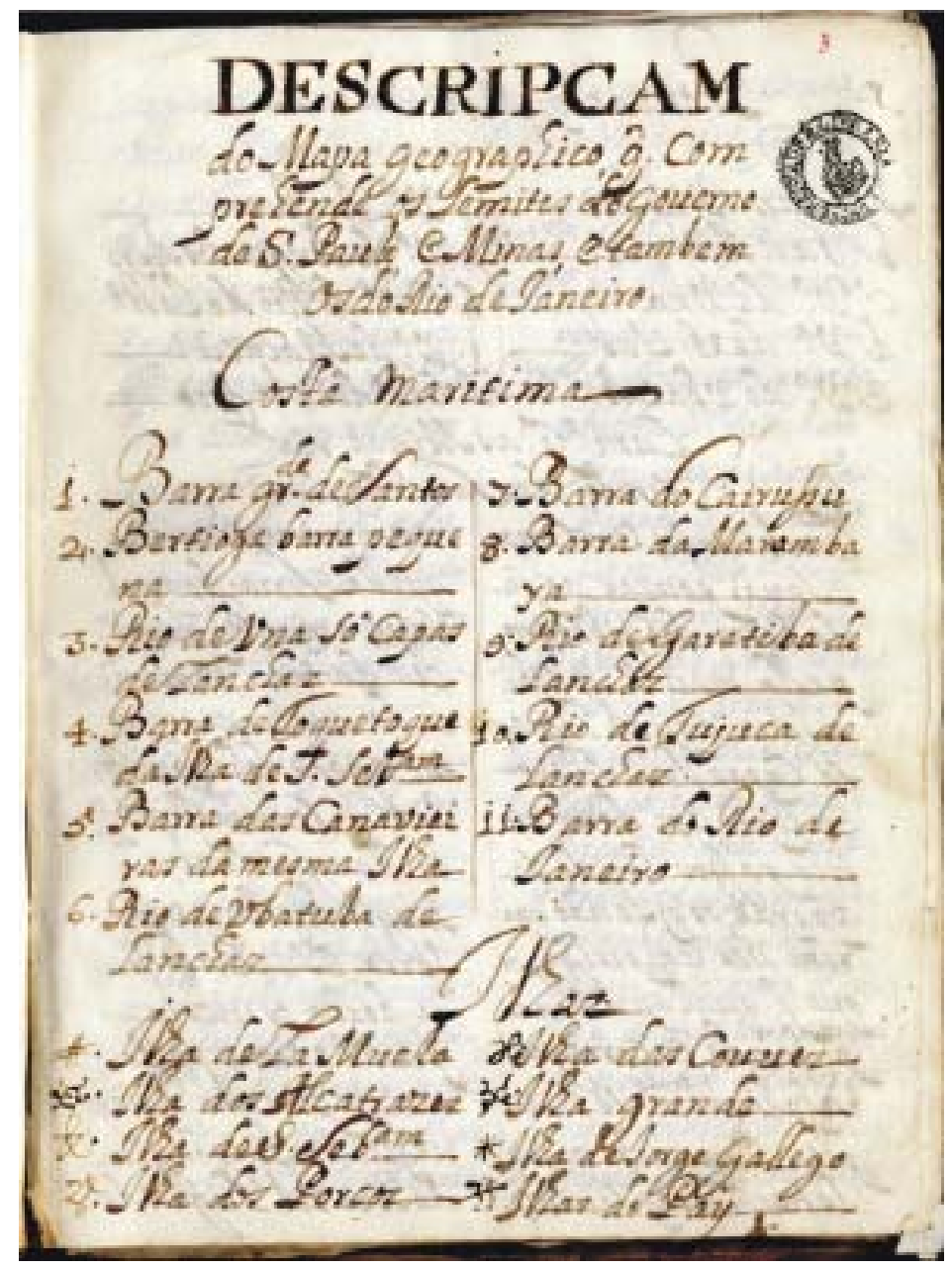

Figura 1: Ms. C (f. 3r) 


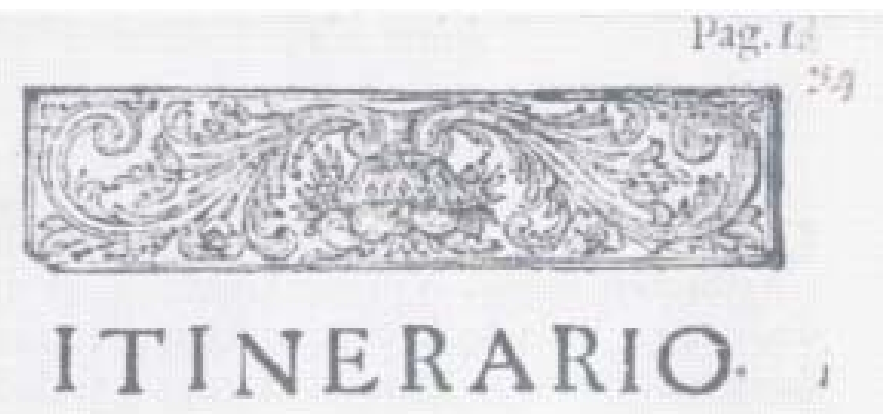

COSTA MARITIMA.

Frg. Arra grande deSantos, Bertioga. Bay-

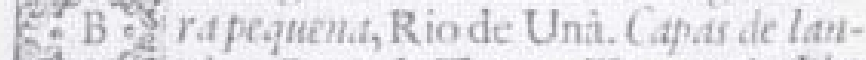

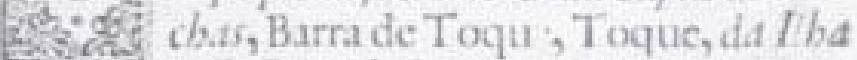
de S. Sebaftiatō, Barra das Caniviciras. Damefina Ill a. Rio Ubatubă, Burra de Cayroçu, Barrade Maranbuya, Riode Garatibà. De louchats, Riode Toyuta. Delancbas, Barrado Rio de Janciro.

\section{L H A S.}

I Lha de Camuella, Thia dosAlcatrazes, Itha deS. Sebuftiaó, Jlha dos Porcos, Ilha das Couves, Itha Grande, Itha de George Gallego, thas do Pay.

$$
\text { A } 4
$$

$\mathrm{PO}-$

Figura 2: DP (p. 4 [= p. I] 


\section{Transcrição}

A transcrição que já se completou é a do testemunho L: a lição é conservadora e seguem-se quase na íntegra as normas de transcrição de documentos antigos já existentes no Brasil, amplamente utilizadas, como em Lobo, ${ }^{16} \mathrm{com}$ algumas modificações. Nesse aspecto, a transcrição que se propõe é mais diplomática do que muitas que vêm sendo efetivadas nos últimos anos, presentes em transcrições como as já citadas de Lobo, Megale e Toledo Neto ${ }^{17}$ ou Megale, Toledo Neto e Fachin, ${ }^{18}$ e outras que, com o objetivo de transcrição de um volume considerável de documentos, optaram pelas normas já mencionadas. A principal diferença entre essas e a que utilizamos (cf. Anexo) é a manutenção das abreviaturas.

Dado nosso objetivo de pesquisa lingüística, preferimos manter um grau baixo de mediação ${ }^{19}$ do editor entre o original e a transcrição, a fim de preservar a língua da época com sua variação, mesmo ortográfica, e pretendemos, na medida das possibilidades gráficas, manter até mesmo o layout original do fólio, no que se refere a colunas, quebras de linha e de fólio, e manutenção das abreviaturas.

Apresentamos aqui a transcrição de dois fólios apenas, devido a limitações de espaço (ff. 1r e 1v do ms. L), precedida por fac-símile do testemunho:

\footnotetext{
${ }^{16}$ LOBO. Cartas baianas setecentistas, p.23-24.

${ }^{17}$ MEGALE;TOLEDO NETO. Por minha letra e sinal, p. 145.

${ }^{18}$ MEGALE;TOLEDO NETO; FACHIN. Caminhando mato dentro, p. 182-184.

${ }^{19}$ CAMBRAIA. Iniciação à crítica textual, p. 93.
} 


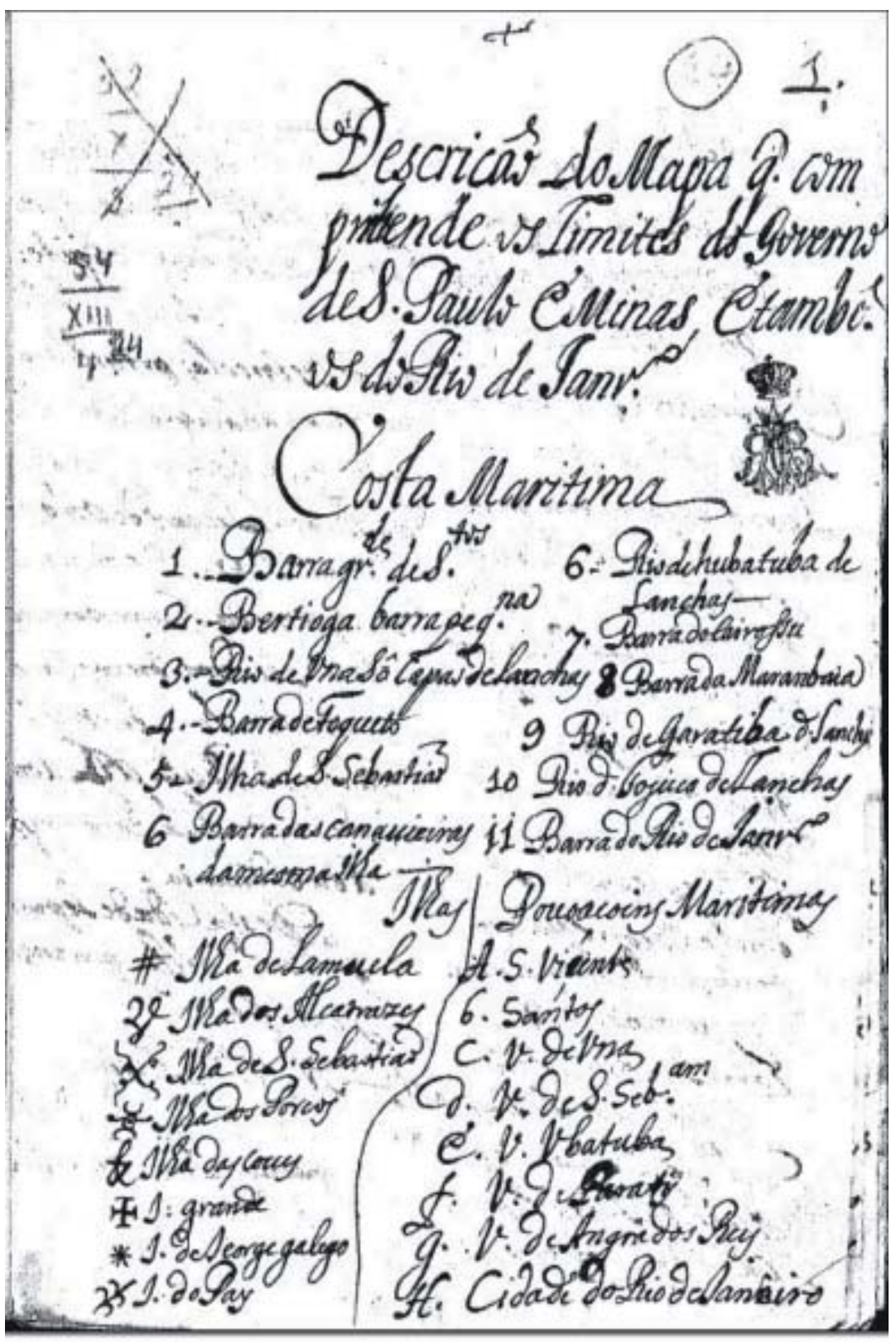

Fólio 01r

Figura 3: Ms. L (f. 1r) 
Descriçaõ do Mapa ̃̃ . com prihende os Limites do Governo deS. Paulo \&Minas \&tambẽ os doRio de Janr ${ }^{\mathrm{o} .20}$

5

\section{Costa Maritima}

1. Barra gr. ${ }^{\text {de }}$ deS. ${ }^{\text {tos }}$

10

2. Bertioga barra peq. ${ }^{\text {na }}$

3. Rio de VnaSõ Capas delanchas

4. Barra deToqueto

5. Ilha deS. Sebastiaõ

6. Barra das canauieiras

15 da mesma ilha
6. Rio dehubatuba de Lanchas

7. Barra doCairossu

8. Barrada Maranbaia

9. Rio de Garatiba d. Lanchas

10. Rio d. Tojuca deLanchas

11. Barra do Rio deJanr ${ }^{\circ}$

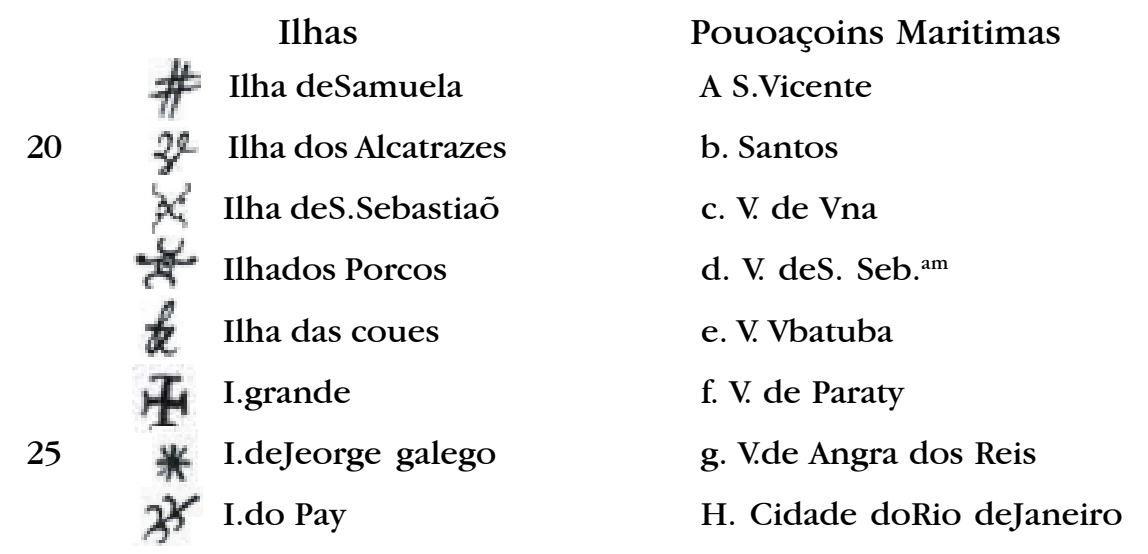

Figura 4: Transcrição do ms. L, f. 1r

${ }^{20}$ Sinais públicos e manuscritos na parte superior direita, central e esquerda do documento. 


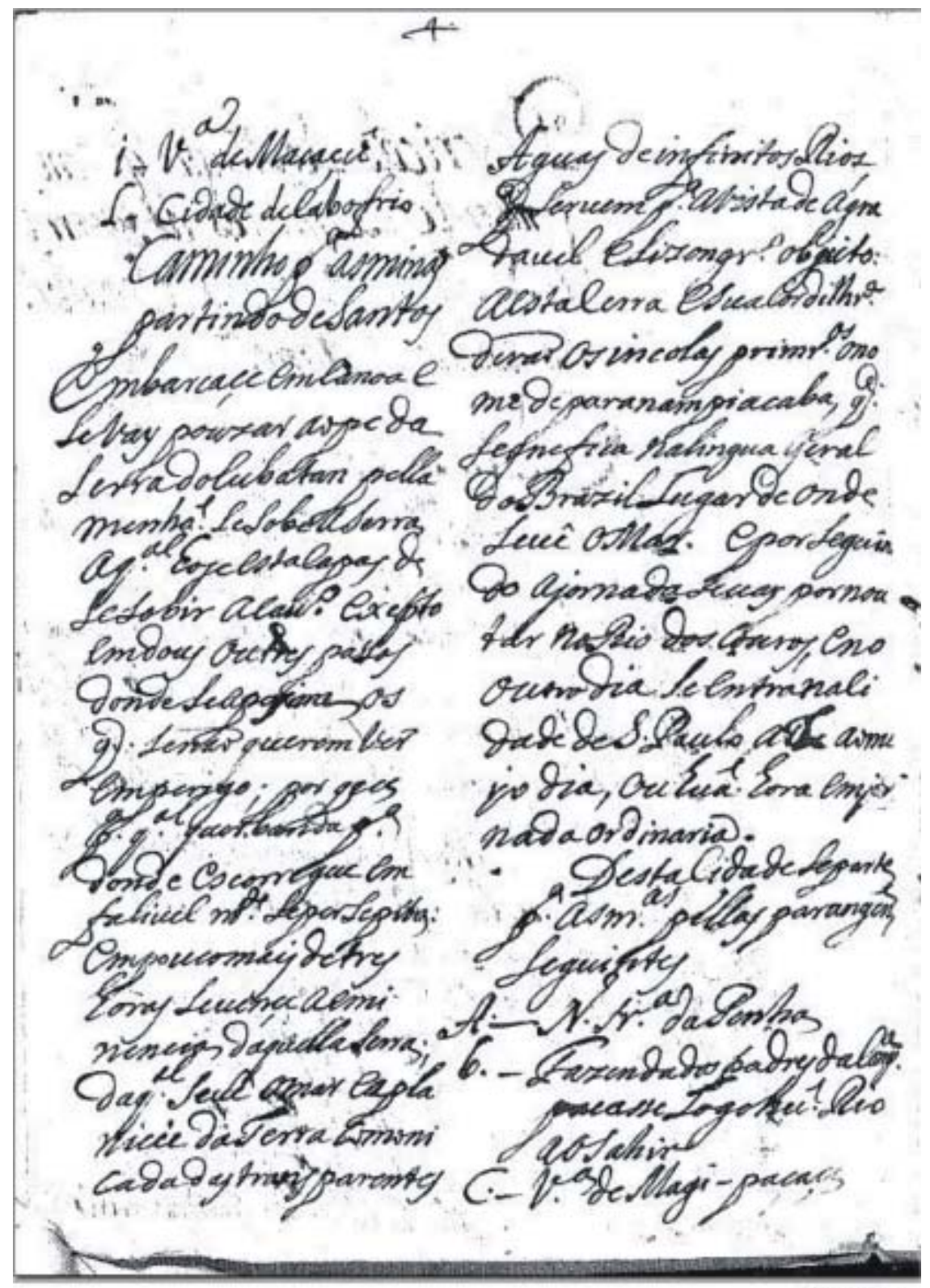

Figura 5: Ms. L (f. 1v) 


\begin{tabular}{|c|c|}
\hline $\mathrm{i}-\mathrm{V}^{\mathrm{a}}$ deMacaçú & Aguas de infinitos Rios \\
\hline L - Cidade deCabofrio & $\tilde{\mathrm{q}}$. servem p. $^{\mathrm{a}}$ avista de agra \\
\hline Caminho $\mathrm{p} .^{\mathrm{a}}$ asminas & davel elizongr ${ }^{\circ}$. objecto: \\
\hline partindo deSantos & aestacerra esua cordilhr ${ }^{\mathrm{a}}$. \\
\hline Embarcaçe emcanoa e & deraõ os incolas primros. ono \\
\hline Sevay pouzar aope da & me de paranampiacaba, $\mathrm{q}^{\sim}$. \\
\hline SerradoCubatan pella & Segnefica nalingua Geral \\
\hline menhã. Sesobe aSerra & doBrazil Lugar de onde \\
\hline aq. ${ }^{\text {al }}$ hoje estacapas de & Sevê oMar. Epor seguin \\
\hline SeSobir acau..$^{\circ}$ exepto & do ajornada Sevay pornou \\
\hline emdous outres passos & tar noRio dos Couros, Eno \\
\hline donde Seapejam os & outro dia Se entranaCi \\
\hline $\mathrm{q}^{\sim} \cdot$ senão querem ver & dade deS. Paulo athe aome \\
\hline emperigo; por que & yo dia, ou huã hora emjor \\
\hline $\mathrm{p}^{\mathrm{a}} \mathrm{q}^{\mathrm{al}}{ }^{\mathrm{al}}$ quer banda $\mathrm{p} .^{\mathrm{a}}$ & nada ordinaria \\
\hline donde escorregue em & [espaço] DestaCidade separte \\
\hline falível $\mathrm{m} .^{\text {te }}$ SeperSepita: & $\mathrm{p}^{\mathrm{a}}$. as $\mathrm{m}^{\mathrm{as}}$. pellas parangens \\
\hline Empoucomais detres & seguintes \\
\hline horas sevençe aemi & A.. - N. Sr ${ }^{\mathrm{a}}$. daPenha \\
\hline nencia daquellaSerra; & b. - Fazendados padres daComp \\
\hline daq. ${ }^{\text {al }}$ sevê omar eapla & pacasse Logohũ. Rio \\
\hline nicie daTerra comoni & aosahir \\
\hline cada das transparentes & C. $-V^{a}$. de Magi - paçaçe \\
\hline
\end{tabular}

Figura 6: Transcrição do ms. L, f. 1v

Como se pode observar nos fólios acima, é significativa a presença de abreviaturas: 14 ocorrências no f. 1r e 20 no 1v. Na passagem correspondente de um dos outros testemunhos manuscritos ( $\mathrm{C}, \mathrm{f}$. 3) há apenas 7 ocorrências de abreviaturas; na da versão impressa (DP, p. 4) não há uma abreviatura sequer.

Esse aspecto abre-se a inúmeras interpretações ligadas à pressa de quem escreve, ao cuidado, ou ao próprio modelo. Sua análise demanda um trabalho à parte e não nos ocuparemos dele 
aqui, registrando somente que, como já se comprovou, essa característica dos textos manuscritos pode se abrir a uma interpretação lingüística.

O trabalho da edição do Mapa geográfico está ainda em andamento, embora tenha tido um avanço considerável a partir dos primeiros estudos. O fato de ser um texto relativo ao Brasil setecentista atribui-lhe um interesse especial, lingüístico e histórico, pois a língua dessa época no Brasil é ainda incipientemente estudada e como se sabe fortemente vinculada a fatores históricos, em sentido lato. $O$ fato de ser politestemunhal também lhe outorga valor, principalmente se considerarmos que a edição de textos em português visando à pesquisa linguística no Brasil tem se ocupado exclusivamente de textos monotestemunhais.

Résumé: On présente dans cet article un texte ancien du XVIII ${ }^{\text {éme }}$ siècle, écrit en portugais, dans lequel l'itinéraire pour les mines d'or en partant de São Paulo et Rio de Janeiro est détaillé. Ce texte se présente en des versions manuscrites et imprimées On montre ici ses principaux caractéristiques ainsi que les étages déjà terminés de son édition.

Mots-clés: Critique textuelle; XVIII ${ }^{\mathrm{ème}}$ siècle, manuscrit; itinéraire. 


\section{Referências}

ANDRADE GOMES, Maria do Carmo. Índice toponímico: nota introdutória. In: CAMPOS, V.; ALMEIDA FIGUEIREDO, L.R. (Orgs.) Códice Costa Matoso. Coleção das notícias dos primeiros descobrimentos das minas na América que fez o doutor Caetano Costa Matoso sendo ouvidor-geral das de Ouro Preto, de que tomou posse em fevereiro de 1749 \& vários papéis. Belo Horizonte Fapemig/Fundação João Pinheiro, 1999. Vol. 2: Glossários. Bibliografia. Índice.

BRITO, Francisco Tavares de. Itinerário geográfico com a verdadeira descrição dos caminhos, estradas, roças, sítios, povoações, lugares, vilas, rios, montes, e serras, que há da cidade de S. Sebastião do Rio de Janeiro até as Minas do Ouro. Revista do Instituto Histórico e Geográfico Brasileiro, Rio de Janeiro, v. 20, p. 430-441, 1956.

BRITO, Francisco Tavares de. Itinerário geográfico com a verdadeira descrição dos caminhos, estradas, roças, sítios, povoações, lugares, vilas, rios, montes, e serras, que há da cidade de S. Sebastião do Rio de Janeiro até as Minas do Ouro. Barroco, Belo Horizonte, v. 4, p. 91-118, 1972.

CAMBRAIA, César Nardelli. Iniciação à crítica textual. São Paulo: Martins Fontes, 2005.

CAMPOS, V.; ALMEIDA FIGUEIREDO, L.R. (Orgs.) Códice Costa Matoso: coleção das notícias dos primeiros descobrimentos das minas na América que fez o doutor Caetano Costa Matoso sendo ouvidor-geral das de Ouro Preto, de que tomou posse em fevereiro de 1749 E vários papéis. Belo Horizonte: Fapemig/Fundação João Pinheiro, 1999.

COHEN, Maria Antonieta A. de M. A gramaticalização de -mente em português: reexame de um caso clássico. Salvador, 2009. (Comunicação apresentada no ROSAE - $1^{\circ}$ Congresso Internacional de Linguística Histórica, na Universidade Federal da Bahia, em Salvador, no período de 26 a 29 de julho de 2009).

DERBY, Orville. Um mapa antigo de parte das capitanias de São Paulo, Minas Gerais e Rio de Janeiro. Revista do Instituto Histórico e Geográfico de São Paulo, São Paulo, v. 2, p. 197-219, 1898.

LIMA Jr., Augusto. A capitania das Minas Gerais: origens e formação. 3. ed. Belo Horizonte: Instituto de História, Letras e Arte, 1965. 
LIVERMORE, L. V. An early published guide to Minas Gerais: the ITINERARIO GEOGRAFICO (1732). Revista da Universidade de Coimbra, v. XXVI, p. 4-10, 1978. (Separata).

LOBO, Tânia (Org.) Cartas baianas setecentistas. São Paulo: Humanitas/ FFLCH-USP, 2001.

MEGALE, Heitor. Bandeira e bandeirante. In: MEGALE, Heitor. (Org.) Filologia bandeirante. São Paulo: Humanitas/FAPESP, 2000. p. 15-48.

MEGAlE, Heitor; TOLEDO NETO, Silvio. (Orgs.) Por minha letra e sinal: documentos do ouro do século XVII. São Paulo: Fapesp, 2006.

MEGALE, Heitor; TOLEDO NETO, Silvio; FACHIN, Pablo R. (Orgs.) Caminhando mato dentro: documentos do ouro do século XVIII. São Paulo: Fapesp/Espaço Editorial, 2009.

SPINA, Segismundo. Introdução à edótica: crítica textual. 2. ed. rev. e atual. São Paulo: Editora da Universidade de São Paulo, 1994.

VENÂNCIO, Renato P. Caminho novo: a longa duração. Varia História, Belo Horizonte, n. 21, p. 181-189, 1999. 


\section{ANEXO \\ Normas para transcrição de documentos manuscritos}

COHEN, M. A. de M. (2009) $)^{21}$

1. A transcrição será conservadora.

2. As abreviaturas serão mantidas na transcrição e desenvolvidas posteriormente em um glossário.

3. Não será estabelecida fronteira de palavras que venham escritas juntas, nem se introduzirá hífen ou apóstrofo onde não houver. Exemplos: deCaboFrio; Embarcaçe; nalingua; sepersipita; em estado deo fazer; Fazendados Padres daComp ${ }^{a}$.

4. A pontuação original será rigorosamente mantida. No caso de espaço maior intervalar deixado pelo escriba, será marcadao: [espaço]. Exemplo: "que podem perjudicar. [espaço] Osdias passaõ eninguem comparece".

5. A acentuação original será rigorosamente mantida, não se permitindo qualquer alteração. Exemplos: Aguas; huã; derão; Mantiquêra

6. Será respeitado o emprego de maiúsculas e minúsculas como se apresentam no original. No caso de alguma variação física dos sinais gráficos resultar de fatores cursivos, não será considerada relevante. Assim, a comparação do traçado da mesma letra deve ser feita.

7. Eventuais erros do escriba ou do copista serão remetidos para nota de rodapé, onde se deixará registrada a lição por sua respectiva correção. Exemplo: "nota 1. Pirassocunda por Pirassonunga"; "nota 2. deligoncia por deligencia"; "nota 3. adverdinto por advertindo".

8. Inserções do escriba ou do copista na entrelinha ou nas margens superior, laterais ou inferior entram na edição entre os sinais $<>$, na localização indicada. Exemplo: < fica definido que olugar convencionado é acasa dePedro nolargo damatriz $>$

${ }^{21}$ As normas que aqui se apresentam são uma adaptação de normas tais como as presentes em LOBO (Cartas baianas setecentistas, p.23.24). Alguns dos exemplos foram trocados e a principal diferença refere-se à manutenção das abreviaturas (item 2). 
9. Supressões feitas pelo escriba ou pelo copista no original serão tachadas. Exemplo: "todos ninguem dospresentes assignarom; sahiram sahiram aspressas para oadro". No caso de repetição que o escriba ou o copista não suprimiu, o editor a coloca entre colchetes duplos. Exemplo: fugi[[gi]]ram emdireçaõ opaço.

10. Intervenções de terceiros no documento original, devem aparecer no final do documento informando-se a localização.

11. Intervenções do editor hão de ser raríssimas, permitindo-se apenas em caso de extrema necessidade, desde que elucidativas a ponto de não deixarem margem a dúvida. Quando ocorrerem, devem vir entre colchetes, Exemplo: "naõ deixe passar neste [conjectura] de Areas".

12. Letra ou palavra não legível por deterioração justificam intervenção do editor na forma do item anterior, com a indicação entre colchetes: [ilegível].

13. Trecho de maior extensão não legível por deterioração receberá a indicação [corroídas +5 linhas]. Se for o caso de trecho riscado ou inteiramente anulado por borrão ou papel colado em cima, será registrada a informação pertinente entre colchetes e sublinhada.

14. A divisão das linhas no documento original será preservada, bem como a mudança de fólio.

15. Na transcrição, as linhas serão numeradas de cinco em cinco a partir da quinta na margem esquerda. Será feita de maneira por fólio.

16. As assinaturas simples ou as rubricas serão sublinhadas. Os sinais públicos serão indicados entre colchetes. Exemplos: assinatura simples: Antonio Martins Ferr ${ }^{\mathrm{a}}$; sinal público: [Bernardo Jose de Lorena].

17. Os fólios serão numerados no canto direito superior da página com o número e a indicação de $\mathbf{r}$ (recto) ou v (verso).

Recebido para publicação em 17 de novembro de 2010

Aprovado em 12 de dezembro de 2010 